\title{
Noscapine Hydrochloride
}

National Cancer Institute

\section{Source}

National Cancer Institute. Noscapine Hydrochloride. NCI Thesaurus. Code C61103.

The orally available hydrochloride salt of the opioid agonist noscapine, a

phthalideisoquinoline alkaloid derived from the opium poppy Papaver somniferum, with

mild analgesic, antitussive, and potential antineoplastic activities. Noscapine binds to

tubulin and alters its conformation, resulting in a disruption of the dynamics of

microtubule assembly (by increasing the time that microtubules spend idle in a paused

state) and subsequently, the inhibition of mitosis and tumor cell death. Unlike other

tubulin inhibitors such as the taxanes and vinca alkaloids, noscapine does not affect

microtubule polymerization. 